\title{
25 Research Square \\ Remote Patient Monitoring for COVID-19 Patients: Comparisons and Framework for Reporting
}

David Joyce ( $\nabla$ joyced4@tcd.ie )

University College Dublin https://orcid.org/0000-0003-3578-2412

\section{Aoife De Brún}

University College Dublin

\section{Sophie Mulcahy Symmons}

University College Dublin

\section{Robert Fox}

University College Dublin

\section{Eilish McAuliffe}

University College Dublin

\section{Research Article}

Keywords: Remote patient monitoring, COVID-19, Reporting guidelines, Framework, Implementation, Technology

Posted Date: August 13th, 2021

DOl: https://doi.org/10.21203/rs.3.rs-788795/v1

License: (c) (i) This work is licensed under a Creative Commons Attribution 4.0 International License. Read Full License 


\section{Abstract}

\section{Background}

Remote patient monitoring (RPM) has been implemented for COVID-19 patients by various health services at speed, without the opportunity to learn one from another. A lack of standardised reporting has hindered evaluation of RPM.

\section{Aims}

The aims of this overview of RPM for COVID-19 patients are twofold:

(1) to provide tabulated, descriptive information for a range of implementations to facilitate familiarization, learning and comparison; and based on this

(2) to develop a framework for reporting to improve reporting consistency as a first step towards the development of reporting guidelines for RPM.

\section{Method}

A rapid review of the literature for RPM for COVID-19 patients was conducted seeking studies that provided details of a specific implementation of RPM with sufficient information to compare one with another. The content of these articles was then reviewed and synthesised to a tabular format under common headings to facilitate ready comparison and to highlight omissions in reporting. Reporting consistencies and inconsistencies between the studies were then considered to develop a framework for reporting.

\section{Results}

The studies suggested key common characteristics outlined under four headings: context, technology, process, and metrics. These were further divided into subheadings to provide a consistent tabular format to aid familiarization. Consideration of consistencies and inconsistencies in reporting suggests the following criteria be used for reporting: Dates, Rationale, Patients, Medical team, Technology provider, Communication mode, Patient equipment, Patient training, Staff training, Markers, Data Input Frequency, Thresholds for Escalation, Discharge and Metrics for: RPM Enrollment, Escalation, Patient acceptance, Staff acceptance, and Patient adherence.

\section{Background}

COVID-19 has challenged health services throughout the world in terms of hospital capacity [1, 2], whilst nosocomial transmission continues to put staff and vulnerable populations at risk of infection $[3,4]$.

In the face of these challenges, remote monitoring of patients in their own homes was considered a potential solution to avoid overburdening hospital capacity and mitigating the risk of nosocomial 
infection. The US based Food and Drugs Administration (FDA) responded early by issuing a policy in March 2020 to facilitate greater use of RPM technologies to reduce hospital visits [5].

RPM has been implemented for COVID-19 patients by various health services. Of necessity, many current implementations of RPM have been introduced independently and at speed, without the opportunity to learn one from another. A paper on how health systems learn from one another suggests that learning from wider contexts is critical in order to improve performance [6].

A systematic review of 27 studies [7] on RPM for COVID-19 sought to determine the impact of remote home monitoring on virtual length of stay, escalation, emergency department attendance/reattendance, admission/readmission and mortality. It was able to determine that most implementations were led by secondary care, that a positive test for COVID-19 was not required in most cases for patient eligibility and that monitoring was conducted via online platforms, paper-based systems with telephone calls or (less frequently) through wearable sensors. However, the review clearly states that it was difficult to carry out an analysis of the impact of remote home monitoring across all examples because not all articles reported data on the same outcomes and that it could not reach substantive conclusions regarding patient safety and the identification of early deterioration due to lack of standardised reporting and missing data.

Guidelines that specify a minimum set of criteria for reporting can improve the accuracy and transparency of publications, thus facilitating easier and more reliable appraisal of quality and relevance [8]. The Equator network [9], set up to actively promote their use, describes a reporting guideline as "A checklist, flow diagram, or structured text to guide authors in reporting a specific type of research, developed using explicit methodology" that "presents a clear list of reporting items that should appear in a paper and explains how the list was developed". To improve the completeness of reporting of mobile health (mHealth) interventions, the WHO mHealth Technical Evidence Review Group developed the mHealth evidence reporting and assessment (mERA) checklist [10]. Whilst aspects of this checklist are pertinent for RPM, no specific checklist for this intervention applied to COVID-19 care currently exists.

\section{Aims}

The aims of this overview of implementations of RPM for COVID-19 patients are twofold:

1. to provide tabulated, descriptive information for a range of implementations to facilitate familiarization, learning and comparison; and from this

2. to develop a framework for reporting to improve reporting consistency as a first step towards the development of reporting guidelines for RPM.

\section{Method}

A rapid systematic review of the literature for RPM for COVID-19 patients was conducted in January 2021 seeking studies published between $1^{\text {st }}$ Jan 2020 and $12^{\text {th }}$ January 2021. Rapid reviews are characterized 
as an accelerated evidence synthesis approach with no clear distinction between rapid reviews and more traditional systematic reviews. However, rapid reviews typically streamline traditional systematic review methods, for example searching, to synthesize evidence in a shorter timeframe, whilst maintaining quality and rigour [11]. Studies that detailed a specific implementation of RPM with sufficient information to compare one with another were included. Studies relating to RPM for illnesses other than COVID-19 or with insufficient information were excluded. The PubMed database was searched with a broad strategy in an effort to identify all relevant studies since January 2020 published in English. The search terms ("Remote Patient Monitoring" OR “Home Monitoring" OR "Virtual Monitoring") AND ("Covid-19") were used. Quality appraisal was not conducted as the articles sought were informational reports of clinical implementations rather than studies designed to answer a research question.

The content of these articles was then reviewed and synthesised to a tabular format under common headings to facilitate ready comparison and to highlight omissions in reporting.

\section{Results}

\subsection{Study Selection}

Figure 1 PRISMA Screening flowchart for study selection.

The PRISMA Screening flowchart for study selection is shown in Figure 1. Of the 15 studies included in this rapid review (Table 1), nine were from the US, two from the UK and one each from Africa, Ireland, China, and the Netherlands.

Table 1 Overview of Studies 


\begin{tabular}{|c|c|c|c|c|}
\hline Ref & $\begin{array}{l}\text { Reporting } \\
\text { Period } \\
\text { (Approx) } \\
(2020)\end{array}$ & Country & $\begin{array}{l}\text { Number } \\
\text { Enrolled }\end{array}$ & Patient Type \\
\hline 12 & NA & US & 83 & Low to moderate risk ED patients \\
\hline 13 & March to May & US & 2652 & Confirmed / presumed COVID-19 \\
\hline 14 & NA & Ireland & 26 & $\begin{array}{l}\text { COVID-19 positive with pulmonary } \\
\text { infiltrates, without current need for } \\
\text { supplemental oxygen }\end{array}$ \\
\hline 15 & April, May & US & 112 & Symptoms consistent with COVID-19 \\
\hline 16 & NA & Rwanda/Uganda & NA & $\begin{array}{l}\text { COVID-19 cases and contacts in home } \\
\text { isolation }\end{array}$ \\
\hline 17 & NA & US & 2000 & $\begin{array}{l}\text { Patients at risk of developing a serious case } \\
\text { of COVID-19 }\end{array}$ \\
\hline 18 & $\begin{array}{l}\text { January, } \\
\text { February }\end{array}$ & China & 188 & $\begin{array}{l}\text { Home quarantined confirmed or suspected } \\
\text { cases }\end{array}$ \\
\hline 19 & April, May & Netherlands & 33 & $\begin{array}{l}\text { COVID-19 patients with clinical improving } \\
\text { trend and oxygen therapy tapered down to a } \\
\text { maximum of } 3 \mathrm{~L} / \mathrm{min} \text {-f }\end{array}$ \\
\hline 20 & April to June & US & 225 & $\begin{array}{l}\text { Patients with COVID-19 upon hospital } \\
\text { discharge }\end{array}$ \\
\hline 21 & May & US & 50 & $\begin{array}{l}\text { Low- and moderate risk COVID- } 19 \text { with } \\
\text { oxygen saturation of }<92 \% \text { during the } \\
\text { hospital stay. }\end{array}$ \\
\hline 22 & March to May & US & 2255 & Patients with COVID-19 symptoms \\
\hline 23 & April to June & US & 924 & $\begin{array}{l}\text { After testing positive to COVID-19 or after } \\
\text { hospital discharge for COVID-19. }\end{array}$ \\
\hline 24 & May to June & UK & 192 & $\begin{array}{l}\text { Patients discharged from the ED with } \\
\text { suspected COVID-19. }\end{array}$ \\
\hline 25 & April to June & UK & 279 & $\begin{array}{l}\text { Patients who were deemed likely to have } \\
\text { COVID-19 pneumonia and were discharged }\end{array}$ \\
\hline 26 & March to May & US & 154 & Confirmed and suspected COVID-19 \\
\hline
\end{tabular}

The studies, when reviewed by the lead author, suggested key common characteristics outlined under four headings: context, technology, process, and metrics with each then divided into 4 sub-headings as shown in Table 2. 


\begin{tabular}{llll} 
Context & Technology & Process & Metrics \\
\hline Dates & Provider & Markers & Patients Enrolled \\
\hline Rationale & Communications Platform & Data Input Frequency & Alerts/Escalations \\
\hline Patients & Patient Equipment & Thresholds & Patient Acceptance \\
\hline Medical Team & Training & Discharge & Patient Adherence \\
\hline
\end{tabular}

Table 2 Headings and sub-headings for synthesis

The studies were then synthesized according to these headings and sub-headings with the results shown in Appendices 1 to 4.

\subsection{Description Of Implementations}

The meanings of these headings along with summaries of reporting from included studies are given below.

\subsubsection{Context (Appendix 1)}

The individuals involved in the RPM implementation, both patients and health care provider staff are covered here, along with the rationale for patient enrollment and the dates on which monitoring occurred.

\section{Dates [The specific time period for the reported RPM]}

Four studies did not explicitly provide the dates covered [12, 14, 16-17]. All studies giving dates dealt with the early stages of the pandemic.

\section{Rationale [Reasons for implementation of RPM]}

Two rationales for RPM were evident from these published studies: COVID-19 positive patients discharged from hospital to enable safe and early discharge with on-going RPM [12, 14, 19, 21, 23-24]; and RPM for suspected or confirmed COVID-19 patients in the community to ensure only those patients who required hospital treatment were admitted $[13,15-18,22,25,26]$. Only one study incorporated both [23].

\section{Patients [Patients included in RPM]}


Patients were described in terms of confirmed or presumed COVID-19 positive [13, 20, 23-24, 26], low to moderate risk [12, 21], at risk of developing serious COVID-19 [17], having symptoms of COVID-19 [15, 18, $22]$, and had or have COVID pneumonia $[14,25]$. The least ill patients were home quarantined suspected cases $[16,18]$ whilst the most complex were patients who, after hospital discharge, still required oxygen therapy at home [19].

\section{Remote Monitoring Medical team [Personnel involved in care of patients included in RPM]}

Most medical teams included nurses and physicians [12-14, 17-19, 21-24], one study also included a psychologist [19] and another a neurosurgeon [15]. Medical trainees were also a feature, supervised by more senior staff $[20,23,26]$. One study noted that RPM allowed staff who were themselves quarantining to continue working from home by providing a service to remotely monitored patients [18].

\subsubsection{Technology (Appendix 2)}

Technology played a major role in most implementations of RPM. However, some implementations did not use specialized technologies, merely phoning patients daily and asking about symptoms. This section covers the provision of technological approaches to RPM, the major messaging mode for transfer of information between patient and provider, the monitoring equipment provided to the patient, along with any training or instruction given to the patient in how to use the equipment.

\section{Provider [Supplier of technology to enable RPM]}

One site described sufficient in-house expertise to develop its own system for monitoring [12]. Some used proprietary systems from suppliers of medical monitoring systems [14-15, 18-21, 23, 26] Others adapted systems that were in use prior to COVID-19 $[13,22]$ with the remainder using non-RPM specific systems such as the standard telephone system or packages [17, 24, 25] like Zoom or WeChat (A Chinese app comparable to WhatsApp). One African implementation used a text-based system from a non-profit orientated Canadian company called WelTel [16].

\section{Communications Platform [Type of communications used for patient to healthcare provider and vice versa]}

One of the essential elements of any RPM system is the transfer of information from the patient to the provider at regular intervals. The method of transfer varies widely with mobile technologies often, but not always, involved. There is also the matter of automated transfer, without provider intervention or involving health care personnel. The simplest method is regular phone calls from care provider personnel to the patient with information transferred by phone. Two studies used this method [24, 25]. A further study [21] used this method initially but given the burden on staff found it was not sustainable and changed to a more automated system from a provider of RPM systems.

Two studies used standard text messaging. One [13] in the US sent a twice daily text message to initiate a text question and response exchange. Another from Africa [16] detailed a very similar system but with a 
daily semi-automated initial text.

Email was used by two systems, one to send a link to a form at the start of monitoring which the patient was "required" to update daily [12], the other sent a link daily to a survey via email [17].

Use of mobile apps for data input and transfer was common, reported in eight RPM implementations [14$15,19-23,26]$.

\section{Patient equipment [medical and other devices used as art of RPM]}

Of the 15 implementations, 11 provided patients with a pulse oximeter on enrollment to enable patients to monitor their blood oxygen levels (SP02). Of these, four also provided a thermometer [17, 12, 20, 26], two provided an oximeter only to high-risk patients $[15,24]$ with the remainder $[14,19,21-22,25]$ provided an oximeter to all patients. In the case where no equipment was provided, three studies incorporated SPO2 and temperature measurements from patient owned oximeters and thermometers $[15,23,24]$. Three studies did not provide any equipment $[13,16,23]$ but one of these $[23]$ used oximetry and temperature measurements where available.

Whilst some studies provided an oximeter and thermometer to high-risk patients, one study provided these to low-risk patients and provided high-risk patients with a cellular-enabled tablet telehealth system that monitored for blood pressure, heart rate, temperature, weight, and oxygen saturation [17].

\section{Patient training [familiarization or training provided to patients specific to RPM]}

7 studies did not mention any patient training or familiarization process [13-14, 16-19, 26]. For those that did, training took one of two forms: 1 ) provision of teaching materials such as leaflets or on-line videos and 2) personal outreach such as nurse contact. Four studies mention provision of teaching materials only [12, 22, 24-25], two used personal outreach only [21, 23] with two providing both[15, 20]. Only one report mentioned a technical support contact [15]. Whilst most studies concerned technical information such as how to use an oximeter or download an app, two [23-24] provided non-technical COVID-19 information relating to home isolation and infection control.

\subsubsection{Process (Appendix 3)}

Process describes various aspects of monitoring: what is monitored - known as markers, how often is it monitored (input frequency) and what thresholds are applied for escalation. It also covers discharge from the monitoring program, typically after a default period without complications, though some studies gave more specific criteria.

\section{Markers [physiologic and other indicators of health status monitored during RPM]}

Patient data monitored, or markers, consists of physiologic data and self-reported symptoms. 
Of the 10 studies that provided information on physiological markers, all included SpO2 [12,14$15,17,19,20-21,23,25,26]$. Heart rate was reported by four $[12,15,17,21]$, and temperature by six $[15,17$, $19-20,23,26]$. Respiratory rate was included by two $[15,21]$ but how this is measured is not noted.

All studies monitored symptoms, with five not indicating what these symptoms were [16-17, 22, 24, 25]. Of the remaining 10 , all monitored for dyspnea, three for cough $[18,20,23]$, diarrhea $[15,18,23]$ and weakness $[18,20,23]$, two for chest pain $[15,18]$, and two for vomiting $[20,23]$.

\section{Data Input Frequency [how often marker information is sent to healthcare provider]}

The frequency of data input by the patient varied across studies. 10 sites required once daily input [12, $15,16,18-20,22-24,26]$; three twice daily $[13,17,21]$ and one 4 times daily [14]. Most studies reported on some type of prompt sent to the patient via the transfer method when input is due. However, two sites requiring once daily input made no mention of prompts, simply stating that the patient was instructed [15] or required [18] to enter data once daily.

\section{Thresholds for Escalation [levels of patient health status that initiate a cause for concern type alert to the healthcare provider]}

Seven of the studies $[13,15,18,20,22-23,26]$ reported that a patient can initiate an escalation themselves at any time via the RPM system.

New or worsening symptoms was specified by nine studies $[12-13,15,17,19-20,22-23,26]$.

For studies that monitored SpO2, a resting value of less than or equal to $94 \%[12,14,15,25]$, less than $92 \%$ [20], less than $90 \%$ [21] or when the difference in levels between resting and post exertion exceeded $5 \%[25]$ resulted in escalation.

One report gave a temperature of greater than $37.91^{\circ} \mathrm{C}$ as a cause for escalation [20]. Heart Rate (HR) threshold criteria for escalation, in beats per minute, were also reported: HR greater than 105 [12], HR greater than 100 [15], HR greater than 115 at rest or greater than 125 twenty seconds post exertion or a difference greater than 10 pre - post exertion [21].

Escalation values for respiratory rate, in breaths per minute, were: greater than 20, [15], greater than 22 at rest or greater than 30 at 20 seconds post exertion or a difference greater than 8 pre - post exertion [21].

\section{Discharge [Conditions under which a patient is discharged from RPM]}

14 days was the typical default timescale for leaving the monitoring programme. Of the studies that gave specific clinical criteria to enable discharge, two required oxygen saturation levels to be greater than $96 \%$ $[12,21]$ for 3 days with one requiring normal oxygen saturation level for 3 days [25]. The normal level was not specified by the studies but is usually considered to be $95 \%$ to $100 \%$ [27]. One of these [12] also 
required a heart rate of less than $100 \mathrm{bpm}$ and a temperature of less than $37.96^{\circ} \mathrm{C}$. One study allowed patients to optionally extend the monitoring period from 14 days to 21 days [20].

\subsubsection{Metrics (Appendix 4)}

Numbers can allow us to appreciate the scale of monitoring more fully for each report and provide comparative information on how many patients required escalation. In this section, we provide the number of patients enrolled in each implementation and the numbers of those who were escalated. Also included here are metrics regarding patient acceptance of RPM and adherence to the data inputting requirements.

\section{RPM Enrollment [Number of patients enrolled in the RPM implementation]}

All but one study reported numbers for patients enrolled in RPM. Four involved between 1,900 and 3,000 patients [13, 17, 22, 23]; six involved between 112 and 295 patients [15, 18, 20, 24, 25, 26]; while four involved between 26 and 83 patients $[12,14,19,21]$

\section{Escalation [Numbers of patients in RPM program requiring intervention beyond baseline care]}

Escalation involved an admittance or readmittance to hospital, or merely a short interaction via phone or video with a health care worker. Only a minority of patients typically escalate. For one large programme with over 2000 patients enrolled, 83\% were managed without escalating to human care [13]. Another, with just under 1000 enrolled, reported that about $10 \%$ of patients presented with symptoms requiring escalation to a virtual provider, and $2 \%$ required admission to hospital [23]. For one of the smaller implementations with 26 enrolled [14], the 26 patients generated 51 alerts, which in turn generated 5 reassessments leading to readmission of 4 patients. However, a study with 83 participants [12] stated that 60 patients triggered an automated flag at least once, 39 patients were escalated to a telehealth consult and 17 patients were referred to the ED.

\section{Patient acceptance of RPM [How well the RPM program was accepted by patients]}

Four studies reported patient feedback on RPM. All reported high acceptance. One reported a high net promoter score of 80 [13]. The net promoter score is a single metric that quantifies the response to a single direct survey question: How likely are you to recommend this service? [28]. 91\% of patients provided feedback in one study using a satisfaction questionnaire based on Consumer Quality Index in General Practice [19], with $97 \%$ of those finding the system user friendly. $46 \%$ provided feedback in another [21] with $94 \%$ saying they would recommend to a friend. $66 \%$ provided feedback in a further study with $99.5 \%$ being likely or very likely to recommend to a friend [25].

\section{Patient Adherence [Compliance with patient requirements to provide health status data to healthcare provider]}


Patients were requested and usually prompted to input their data to the system on a regular basis. How well they complied, or patient adherence, has been indicated by 8 of the studies to varying extents. Adherence varied. One study involving hospital discharge [14] that prompted patients 4 times daily for input showed a median daily input of 3.9 for those that did not require readmission and 5.7 for those readmitted, indicating high adherence. Another study involving hospital discharge requiring daily input indicated that patients were monitored for an average of 21.8 days and completed an average of 14.5 daily survey responses suggesting a somewhat lower adherence [12]. A study sending twice daily checkin prompts saw a $59.7 \%$ response to both, $27.5 \%$ to one and $12.8 \%$ to neither [13].

\subsection{Reporting Consistency}

The types of information reported on varied across studies. Four did not provide any date information [12, $14,16,17]$; seven did not provide details of patient training [13-14, 16-19 26]; one did not provide information on markers or input frequency [24]; two did not provide details of escalation thresholds [16,18]; four did not indicate discharge conditions [15, 17-19]; one did not indicate number of patients enrolled [16]; two did not indicate number of escalations [16,17]; eleven gave no indication of patient acceptability $[12,14-18,20,22-24,26]$ and seven gave no indication of patient adherence $[9,16-18,24-$ 26]. None mentioned staff training or staff acceptance. This is not a criticism of any study but strongly indicates a need for greater consistency in reporting of RPM implementations to support learning and meaningful comparison.

\subsection{Framework}

Based on the headings derived from synthesis of the studies, with the addition of health staff acceptance and training mirroring patient considerations, we propose a framework of criteria for reporting of RPM for COVID-19 patients shown in table 3. 


\begin{tabular}{lll} 
Criteria & $\begin{array}{l}\text { Item } \\
\text { no }\end{array}$ & Notes \\
\hline Dates & 1 & Clearly state the implementation dates covered by the study. \\
\hline Rationale & 2 & $\begin{array}{l}\text { State the specific purpose and context of the implementation, e.g., } \\
\text { step-down, preserve bed capacity, increase personnel efficiency, } \\
\text { prevent iatric outcomes }\end{array}$
\end{tabular}

\begin{tabular}{|c|c|c|}
\hline Patients & 3 & $\begin{array}{l}\text { State type of patient catered for by implementation, illness severity, } \\
\text { suspected or confirmed cases etc. }\end{array}$ \\
\hline Medical team & 4 & $\begin{array}{l}\text { Detail range of medical personnel involved in the implementation: } \\
\text { roles, medical specialties, seniority, dedicated or shared etc. }\end{array}$ \\
\hline $\begin{array}{l}\text { Technology } \\
\text { provider }\end{array}$ & 5 & $\begin{array}{l}\text { Provide details of the technology provider: inhouse build, adoption of } \\
\text { system already in place, commercial provider along with name and } \\
\text { head-office location. }\end{array}$ \\
\hline
\end{tabular}

Communication 6 Detail the provider patient mode of communication e.g., text, web form, mode phone call, smartphone app

$\begin{array}{lll}\begin{array}{l}\text { Patient } \\ \text { equipment }\end{array} & 7 \quad \begin{array}{l}\text { Describe the type and make of patient equipment utilized and detail } \\ \text { how it is provided e.g. user provided, provided by healthcare system } \\ \text { and how it is delivered and returned. }\end{array}\end{array}$

Patient training 8 Describe what patient training is provided regarding equipment, procedures and self-care and how this training is conducted
Staff training 9 Describe what staff training is provided regarding equipment, procedures and communication with patients and how this training is conducted

$\begin{array}{lll}\text { Markers } & 10 \quad \begin{array}{l}\text { Detail what is monitored and how, specifically physiologic markers } \\ \text { and self-reported symptoms. }\end{array}\end{array}$

Data Input $\quad 11$ Detail how often patient data is input to the RPM system, whether Frequency done automatically or manually by the patient and describe the frequency and mode of any prompts for input provided to the patient by the system. Outline the procedure followed when input is not received.

Thresholds for 12 Escalation

12 Clearly present the escalation procedure. Detail marker thresholds that trigger a cause for concern alert and how such an alert is sent and received. Detail the number and types of escalation stages, e.g., initial screening by paramedic followed, if deemed apt, by further escalation to physician.

Discharge

State the conditions under which a patient is discharged from RPM e.g., after certain duration, marker thresholds, clinical judgement.

Metric-RPM

Enrollment

Metric-

Escalation

Metric-Patient 16
14 Clearly state the number of patients monitored over the course of the reported implementation along with subgroup breakdowns.

15 Provide numbers for cause for concern alerts, and escalations by level. 
acceptance of

RPM

Metric - Staff acceptance of

RPM

Metric-Patient

Adherence suitable instrument.

17 Provide some indication of staff acceptance using suitable scale

Report on the frequency of patient data input compared to the prescribed frequency.

Table 3 Framework for planning and reporting on RPM implementations for COVID-19 patients.

\section{Discussion}

This study explored descriptive reports of RPM programmes to illustrate the variety of, and provide details on, such programmes in a manner that facilitates rapid familiarisation for any individual or organisation planning or evaluating an RPM programme. It is not the intention here to determine whether one mode of implementation is better than another. However, the wide variety seen in the studies is a matter of worthy of comment.

The RPM implementations described here were put in place in the early stages of the pandemic, so perhaps it is not surprising that there is a high level of variation. Even within individual studies, changes occurred as lessons were learnt over time with one programme [21] abandoning an initial attempt to monitor by phoning patients in favour of a more automated monitoring, due to high demands on personnel. Similarly, another study [13] increased the number of symptoms monitored only to drop back to the original number due to a resulting large increase in unwarranted escalation calls.

The equipment provided to patients varied. The use of pulse oximetry in RPM for COVID-19 is well demonstrated here and is itself a separate subject of research [29]. However, not all health systems will be able to provide the required devices. It is interesting, therefore, to note that several studies from health systems in advanced and developing countries with varying degrees of resource availability used only self-reported symptom data. A study in China [18] developed a set of quarantine management scales concluding that these worked well in identifying patients with disease progression. Somewhat contrary to this, a UK study bemoaned the fact that pulse oximeters were not used more stating that their qualitative experience was that pulse oximetry enhanced telephone assessment of patients, but there was low use as specific criteria were applied for provision of a pulse oximeter. They note that minimising clinical gatekeeping could enhance uptake of this inexpensive but clinically valuable intervention [24].

Wide variation is also seen in the infrastructure used for RPM ranging from nothing more elaborate than the standard telephone system to proprietary systems from companies specialising in remote patient monitoring. Markers also varied, ranging from simple report of symptoms only to combined physiological measures such as heart rate, SPO2 and respiratory rate. Thresholds for escalation ranged from a selfreport on worsening symptoms to algorithms using personalised thresholds. 
It remains to be seen how much increased complexity and sophistication might enhance patient outcomes.

Information reported on also varied, again perhaps due to the studies being conducted at the early stages of the pandemic. Regarding the importance of reporting consistency in the area of RPM, we note once again the comments made in a systemic review on RPM for COVID-19 where the authors stated that it was difficult to carry out an analysis of the impact of remote home monitoring across all examples in the review because not all articles reported data on the same outcomes and that it could not reach substantive conclusions regarding patient safety and the identification of early deterioration due to lack of standardised reporting and missing data [7].

Two reporting guidelines already developed have relevance to RPM, the CONSORT E-health guidelines [30] and the mERA checklist [10]. The CONSORT guidelines seek to improve and standardize evaluation reports of web-based and mobile health interventions, whilst the mERA checklist, developed by the WHO mHealth Technical Evidence Review Group, seeks to standardise the quality of mHealth evidence reporting, and so indirectly improve the quality of mHealth evidence. However, these guidelines are broad in scope, designed to cover a wide range of mobile health and e-health studies. The framework developed here deals specifically with RPM for COVID-19 and so addresses topics of increased relevance to this area. Using the framework will enhance consistency and aid analysis across studies.

\section{Limitations}

Whilst the search for information conducted for this study was thorough; it was limited to studies reporting sufficient information on implementations to provide meaningful comparisons and did not consider health outcomes. As such, certain aspects of RPM may be omitted. This review largely considers aspects of clinical implementation and does not include non-clinical matters such as purchase and storage of monitoring equipment or cost-benefit analysis.

\section{Future Research}

We believe that the information presented here will allow for rapid familiarisation for those seeking an overview of RPM for COVID-19 and, by using the suggested framework, enhance the consideration and reporting of planned and existing RPM implementations for COVID-19. The work here also suggests areas for future research.

The difference in implementations suggests the need for further research to determine if and under what conditions a simple implementation of RPM involving a phone call or text to report on symptoms is adequate, and under what conditions increased benefits may ensue with increasing complexity. This may be particularly important for developing countries as they tackle the pandemic. The details outlined in this study can help inform what needs to be included in such studies. 
Future research may also extend the framework to include more non-clinical aspects of RPM, such as reporting on cost-benefit analysis and technical integration.

The reporting framework presented here may be seen as an initial step towards a more robust set of reporting guidelines with future research advancing the framework, using a Delphi methodology or similar, to inform standardised reporting guidelines for work of this nature.

\section{Declarations}

Competing interests: The authors declare no competing interests.

\section{References}

1. Weissman GE, Crane-Droesch A, Chivers C, Luong T, et al. Locally informed simulation to predict hospital capacity needs during the COVID-19 pandemic. Annals of internal medicine. $2020 \mathrm{Jul}$ 7;173(1):21-8.

2. lacobucci G. Covid-19: all non-urgent elective surgery is suspended for at least three months in England. BMJ: British Medical Journal (Online). 2020 Mar 18;368.

3. Shah AS, Wood R, Gribben C, et al. Risk of hospital admission with coronavirus disease 2019 in healthcare workers and their households: nationwide linkage cohort study. bmj. 2020 Oct 28;371.

4. Nguyen LH, Drew DA, Graham MS, et al. Risk of COVID-19 among front-line health- care workers and the general community: a prospective cohort study. The Lancet Public Health. 2020 Sep 1;5(9):e47583.

5. U.S. Food and Drug Administration . Enforcement Policy for Non-Invasive Remote Monitoring Devices Used to Support Patient Monitoring During the Coronavirus Disease 2019 (COVID-19) Public Health Emergency (Revised), https://www.fda.gov/media/136290. Accessed 17 November 2020.

6. Witter S, Anderson I, Annear P, Awosusi A, Bhandari NN, Brikci N, Binachon B, Chanturidze T, Gilbert K, Jensen $C$, Lievens $T$. What, why and how do health systems learn from one another? Insights from eight low-and middle-income country case studies. Health research policy and systems. 2019 Dec;17(1):1-3.

7. Vindrola-Padros, C., Singh, K., Sidhu, M. S., Georghiou, T., Sherlaw-Johnson, C., Tomini, S. M., ... \& Fulop, N. J. (2021). Remote home monitoring (virtual wards) during the COVID-19 pandemic: a systematic review. MedRxiv, 2020-10.

8. Altman, D. G., Simera, I., Hoey, J., Moher, D., \& Schulz, K. (2008). EQUATOR: reporting guidelines for health research. Open Medicine, 2(2), e49.

9. EQUATOR Network. What is a Reporting Guideline? https://www.equator-network.org/about-us/whatis-a-reporting-guideline/. Accessed 20 January 2021.

10. Agarwal S, LeFevre AE, Lee J, L'engle K, MehI G, Sinha C, Labrique A. Guidelines for reporting of health interventions using mobile phones: mobile health (mHealth) evidence reporting and 
assessment (mERA) checklist. bmj. 2016 Mar 17;352.

11. Kelly, S. E., Moher, D., \& Clifford, T. J. (2016). Defining rapid reviews: a modified Delphi consensus approach. International journal of technology assessment in health care, 32(4), 265-275.

12. Aalam AA, Hood C, Donelan C, et al. Remote patient monitoring for ED discharges in the COVID-19 pandemic. Emergency Medicine Journal. 2021 Mar 1;38(3):229-31.

13. Morgan AU, Balachandran M, Do D, Lam D, Parambath A, Chaiyachati KH, Bonalumi NM, Day SC, Lee KC, Asch DA. Remote Monitoring of Patients with Covid-19: Design, implementation, and outcomes of the first 3,000 patients in COVID Watch. NEJM Catalyst Innovations in Care Delivery. 2020 Jul $21 ; 1(4)$.

14. O'Carroll O, MacCann R, O'Reilly A, et al. Remote monitoring of oxygen saturation in individuals with COVID-19 pneumonia. European Respiratory Journal. 2020 Aug 1;56(2).

15. Tabacof L, Kellner C, Breyman E, Dewil S, Braren S, Nasr L, Tosto J, Cortes M, Putrino D. Remote Patient Monitoring for Home Management of Coronavirus Disease 2019 in New York: A CrossSectional Observational Study. Telemedicine and e-Health. 2020 Oct 13.

16. Nachega JB, Leisegang R, Kallay O, Mills EJ, Zumla A, Lester RT. Mobile health technology for enhancing the COVID-19 response in Africa: a potential game changer?. The American journal of tropical medicine and hygiene. 2020 Jul;103(1):3.

17. Crane SJ, Ganesh R, Post JA, Jacobson NA. Telemedicine Consultations and Follow-up of Patients With COVID-19. InMayo Clinic Proceedings 2020 Sep 1 (Vol. 95, No. 9, pp. S33-S34). Elsevier

18. Xu H, Huang S, Qiu C, Liu S, Deng J, Jiao B, Tan X, Ai L, Xiao Y, Belliato M, Yan L. Monitoring and Management of Home-Quarantined Patients with COVID-19 using a WeChat-based telemedicine system: retrospective cohort study. Journal of medical Internet research. 2020;22(7):e19514.

19. Grutters LA, Majoor KI, Mattern ES, Hardeman JA, van Swol CF, Vorselaars AD. Home telemonitoring makes early hospital discharge of COVID-19 patients possible. Journal of the American Medical Informatics Association: JAMIA. 2020 Nov;27(11):1825.

20. Gordon WJ, Henderson D, DeSharone A, Fisher HN, Judge J, Levine DM, MacLean L, COVID-19 Patients. Applied clinical informatics. 2020 Oct;11(05):792-801.

21. Kodama R, Arora S, Anand S, Choudhary A, Weingarten J, Francesco N, Chiricolo G, Silber S, Mehta $\mathrm{PH}$. Reengineering the Discharge Transition Process of COVID-19 Patients Using Telemedicine, Remote Patient Monitoring, and Around-the-Clock Remote Patient Monitoring from the Emergency Department and Inpatient Units. Telemedicine and e-Health. 2020 Dec 14.

22. Annis T, Pleasants S, Hultman G, Lindemann E, Thompson JA, Billecke S, Badlani S, Melton GB. Rapid implementation of a COVID-19 remote patient monitoring program. Journal of the American Medical Informatics Association. 2020 Aug;27(8):1326-30.

23. Medina M, Babiuch C, Card M, Gavrilescu R, Zafirau W, Boose E, Giuliano K, Kim A, Jones R, Boissy A. Home monitoring for COVID-19. Cleveland Clinic journal of medicine. 2020 May 14.

24. Bell LC, Norris-Grey C, Luintel A, Bidwell G, Lanham D, Marks M, Baruah T, O'Shea L, Heightman M, Logan S. Implementation and evaluation of a COVID-19 rapid follow-up service for patients 
discharged from the emergency department. Clinical Medicine. 2021 Jan;21(1):e57.

25. Nunan J, Clarke D, Malakouti A, Tannetta D, Calthrop A, Xu XH, Chan NB, Khalil R, Li W, Walden A. Triage Into the Community for COVID-19 (TICC-19) Patients Pathway-Service evaluation of the virtual monitoring of patients with COVID pneumonia. Acute medicine. 2020 Jan 1;19(4):183-91.

26. Ford D, Harvey JB, McElligott J, King K, Simpson KN, Valenta S, Warr EH, Walsh T, Debenham E, Teasdale $\mathrm{C}$, Meystre S. Leveraging health system telehealth and informatics infrastructure to create a continuum of services for COVID-19 screening, testing, and treatment. Journal of the American Medical Informatics Association. 2020 Dec;27(12):1871-7.

27. Mayo Clinic Staff. Hypoxemia.

https://www.mayoclinic.org/symptoms/hypoxemia/basics/definition/sym-20050930. Accessed on 23 December 2020.

28. Hamilton, D. F., Lane, J. V., Gaston, P., Patton, J. T., Macdonald, D. J., Simpson, A. H. R. W., \& Howie, C. R. (2014). Assessing treatment outcomes using a single question: the net promoter score. The bone \& joint journal, 96(5), 622-628.

29. Greenhalgh T, Knight M, Inda-Kim M, Fulop NJ, Leach J, Vindrola-Padros C. Remote management of covid-19 using home pulse oximetry and virtual ward support. bmj. 2021 Mar 25;372.

30. Eysenbach G, Consort-EHEALTH Group. CONSORT-EHEALTH: improving and standardizing evaluation reports of Web-based and mobile health interventions. Journal of medical Internet research. 2011;13(4):e126.

\section{Figures}

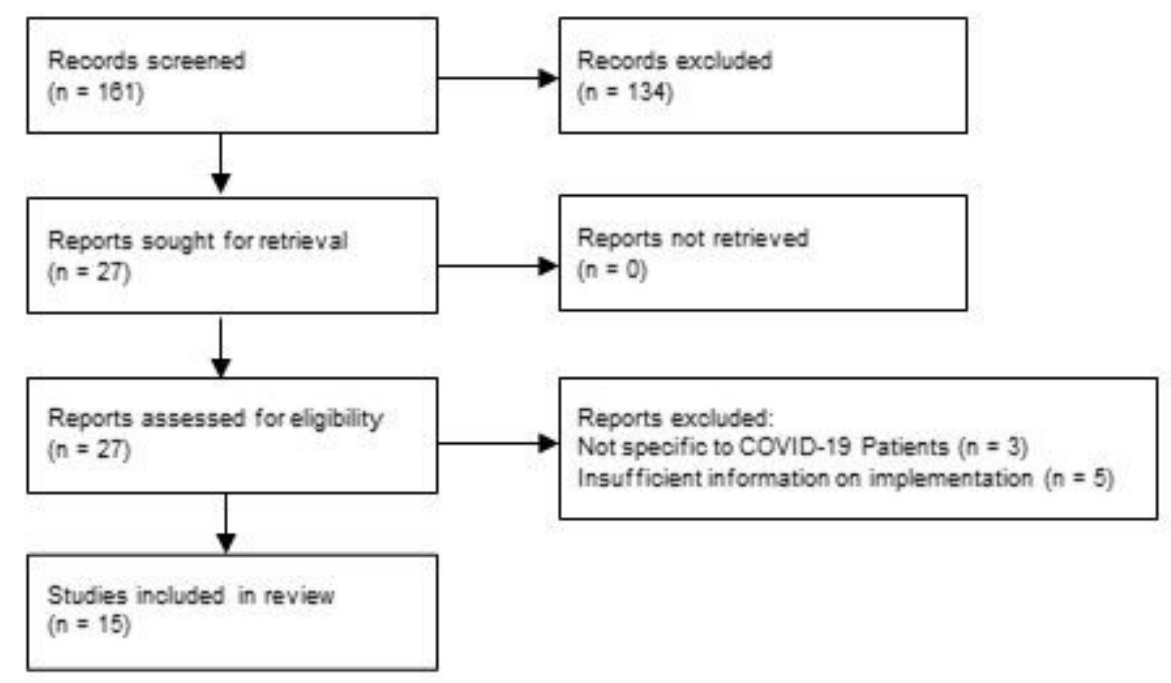

\section{Figure 1}


PRISMA Screening flowchart for study selection. The PRISMA Screening flowchart for study selection is shown in Figure 1. Of the 15 studies included in this rapid review (Table 1), nine were from the US, two from the UK and one each from Africa, Ireland, China, and the Netherlands.

\section{Supplementary Files}

This is a list of supplementary files associated with this preprint. Click to download.

- appendix.docx 